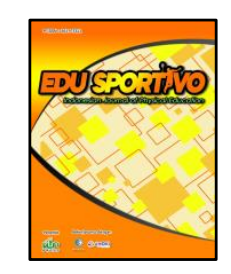

\title{
Efektivitas metode resiprokal terhadap keterampilan dasar bermain sepakbola: Studi eksperimen
}

\section{Effectiveness of reciprocal methods on basic skills in playing football: An experimental study}

\author{
${ }^{* 1}$ Rusmanto, ${ }^{2}$ Rola Angga Lardika, ${ }^{3}$ Muspita
}

*1,2 Pendidikan Jasmani Kesehatan dan Rekreasi, Universitas Riau, Pekanbaru, Indonesia
3Pendidikan Jasmani Kesehatan dan Rekreasi, Universitas Islam Riau, Pekanbaru, Indonesia

Received: 20 June 2020; Accepted 25 July 2020; Published 04 August 2020

OPEN $\odot$ ACCESS

\begin{abstract}
ABSTRAK
Tujuan dari penelitian ini adalah untuk mengungkap pengaruh metode resiprokal pada keterampilan dasar bermain Football. Jenis penelitian ini adalah eksperimen semu, populasi penelitian ini adalah 57 siswa putra SMP Negeri 2 Bunut Kabupaten Pelalawan, Provinsi Riau, sedangkan sampel dalam penelitian ini adalah 40 siswa setelah menggunakan teknik purposive sampling. Instrumen penelitian yang digunakan adalah tes kecakapan David Lee yang merupakan pengembangan dari David Lee yang dibuat oleh Subagyo Irianto. Data dianalisis menggunakan uji normalitas statistik dan uji-t. Hasil analisis data menunjukkan bahwa ada pengaruh metode resiprokal yang signifikan terhadap keterampilan dasar bermain sepak bola untuk siswa SMP Negeri 2 Bunut Kabupaten Pelalawan, Provinsi Riau.
\end{abstract}

Kata Kunci: Resiprokal; Metode; Sepakbola

*Corresponding Author

Email: rusmanto@lecturer.unri.ac.id

\section{ABSTRACT}

The purpose of this study is to reveal the effect of the reciprocal method on the basic skills of playing Football. This type of research is quasi-experimental, the study population was 57 male students of SMP Negeri 2 Bunut Pelalawan Regency, Riau Province, while the sample in this study was 40 students after using purposive sampling technique. The research instrument used was the David Lee proficiency test which was a development of David Lee made by Subagyo Irianto. Data were analyzed using statistical normality test and t-test. The results of data analysis showed that there was a significant influence of reciprocal methods on the basic skills of playing soccer for students of SMP Negeri 2 Bunut, Pelalawan Regency, Riau Province.

Keywords: Reciprocal; Methods; Football

Copyright (C) 2020

Edu Sportivo: Indonesian Journal of Physical Education

https://doi.org/10.25299/es:ijope.2020.vol1(1).5165

How To Cite: Rusmanto., Lardika, R. A., \& Muspita. (2020). Efektivitas metode resiprokal terhadap keterampilan dasar bermain sepakbola: Studi eksperimen. Edu Sportivo: Indonesian Journal of Physical Education, 1(1), 1-8. https://doi.org/10.25299/es:ijop e.2020.vol1(1).5165.

\section{PENDAHULUAN}

Olahraga merupakan bagian dari kehidupan manusia. Kegiatan olahraga dibagi menjadi 3 tujuan yaitu olahraga untuk pendidikan, olahraga untuk rekreasi dan olahraga untuk prestasi (Lardika, 2019). Berolahraga dapat meningkatkan kesegaran jasmani atau kondisi fisik seseorang sehingga dapat melaksanakan aktivitas sehari-hari tanpa mengalami kelelahan yang berarti. Melalui kegiatan olahraga dapat membentuk manusia yang sehat jasmani dan memiliki watak disiplin serta sportifitas yang tinggi dan pada akhirnya membentuk manusia yang berkualitas. Perkembangan olahraga di Indonesia sekarang ini terasa semakin maju, hal ini tidak terlepas dari peran serta 
masyarakat yang semakin sadar dan mengerti arti penting fungsi olahraga itu sendiri, di samping adanya perhatian serta dukungan pemerintah juga menunjang perkembangan olahraga di Indonesia. Praktisi bidang olahraga untuk memperhatikan kualitas latihan yang sesuai untuk meningkatkan kualitas vital paru, karena ini penting untuk menentukan prestasi puncak yang kita inginkan (Rusmanto, Lardika, \& Gazali, 2020).

SMP Negeri 2 Bunut, merupakan salah satu lembaga pendidikan resmi yang memiliki peranan dalam membina dan mengembangkan pendidikan jasmani dan olahraga siswa di Kabupaten Pelalawan Provinsi Riau khususnya dalam olahraga sepakbola. Pendidikan jasmani merupakan aspek terpenting dalam membangun karakter siswa (Lardika \& Tulyakul, 2020). Hal ini senada dengan penjelasan Zainur, Lardika, Gazali, Daharis, dan Sulastio (2020) Melalui aktifitas fisik seseorang akan dapat menjaga kualitas gerak, selain itu pendidikan jasmani juga secara tidak langsung mempengaruhi perkembangan fisik dan mental siswa karena kedekatan hubungan dengan kehidupan nyata. Salah satu upaya yang dapat dilakukan SMP Negeri 2 Bunut adalah mengajarkan dan mengembangkan keterampilan dasar pada siswa melalui mata pelajaran pendidikan jasmani maupun melalui kegiatan ekstrakurikuler di sekolah.

Pentingnya penguasaan dasar bermain sepakbola di Sekolah Menengah Pertama sebagai gambaran tingkat kemampuan dan keterampilan yang dimiliki adalah untuk menghadapi Liga Pendidikan Indonesia (LPI) yang biasanya diadakan setiap tahun. Agar dapat menguasai keterampilan dasar bermain sepakbola, siswa harus berlatih dengan benar dan kontinyu terhadap semua faktor yang menentukan atau mempengaruhi penguasaan keterampilan dasar bermain sepakbola tesebut.

Prestasi SMP Negeri 2 Kecamatan Bunut yang didapatkan melalui kegiatan ekstrakurikuler sepakbola dua tahun yang lalu cukup menjanjikan, karena siswa SMP Negeri 2 Kecamatan Bunut meraih juara pertama Liga Pendidikan Indonesia (LPI) di Kabupaten Pelalawan pada tahun 2012 dan juara dua pada tahun 2013. Akan tetapi pada tahun 2014 mengalami penurunan prestasi dan tidak mendapatkan gelar apapun, hal ini disebabkan karena keterampilan dasar sepakbola pada siswa SMP Negeri 2 Kecamatan Bunut masih kurang baik.

Hal ini dapat diketahui dari pengamatan peneliti saat siswa melakukan latihan masih terdapat kesalahan-kesalahan dalam pelaksanaan teknik dasar sepakbola. Kesalahan ini seperti saat siswa melakukan passing atau mengoper bola sering tidak tepat ke sasaran atau mengarah ke temannya, sedangkan pada saat mengontrol bola atau memberhentikan bola dengan kaki atau dada, bola yang dikontrol selalu lepas dan mudah direbut lawan. Begitu juga pada saat dribbling atau menggiring bola terlihat kurang baik, dan pada saat menyundul bola terlihat siswa sedikit kaku dan bola tidak tepat mengenai dahi, selanjutnya pada saat melakukan shooting atau menendang bola banyak kesalahan teknik yang terlihat misalnya pada saat menendang masih ada yang menggunakan ujung kaki dan pada saat menendang ke gawang sering tidak mengarah ke gawang.

Tentu saja rendahnya keterampilan dasar bermain sepakbola tersebut tidak berdiri sendiri, hal ini dipengaruhi oleh sejumlah faktor apakah yang bersifat internal maupun eksternal. Faktor internal yang mempengaruhi seperti kondisi fisik yang dimiliki siswa sangat mempengaruhi keterampilan dasar bermain sepakbola (Smith et al., 2016). Siswa yang memiliki kondisi fisik yang bagus diduga akan mampu menjalani program latihan yang diberikan pelatih atau guru, berat atau ringan intensitas yang diberikan akan bisa dijalaninya dengan baik (Weng et al., 2018). Sebaliknya, siswa yang tidak memiliki kondisi fisik yang bagus kesulitan dalam menjalani serangkaian latihan yang diberikan pelatih atau guru, selanjutnya motivasi siswa dalam menjalani proses latihan 
mempengaruhi penguasaan keterampilan bermain sepakbola. Mereka yang memiliki motivasi yang bagus akan selalu berusaha mempelajari setiap gerakan teknik sepakbola. Sebaliknya, siswa yang tidak memiliki motivasi akan malas mempelajarinya, mereka cenderung menunggu disuruh dulu oleh pelatih.

Metode pembelajaran yang digunakan guru di sekolah seperti metode komando, metode elementer, metode latihan, metode cakupan atau inklusi, metode konvergen dan divergen, dan masih banyak lagi metode-metode pembelajaran lainnya. Perlu untuk menentukan metode pembelajaran yang mampu meningkatkan hasil belajar siswa dalam penguasaan keterampilan dasar bermain sepakbola (Cvetković et al., 2018). Maka dalam penelitian ini akan dicobakan satu metode mengajar yang diterapkan dalam proses pembelajaran keterampilan dasar bermain sepakbola yaitu metode resiprokal.

Metode resiprokal adalah suatu metode mengajar yang memberikan kesempatan kepada siswa untuk memberikan umpan balik kepada temannya sendiri (Abduljabar, 2010). Memperkenalkan keterampilan kepada siswa merupakan suatu upaya untuk memotivasi siswa belajar. Agar tujuan tersebut tercapai, upaya memperkenalkan keterampilan tadi harus dikaitkan dengan makna dan manfaat bagi siswa yang bersangkutan. Para ahli sepakat bahwa memberikan penjelasan tentang manfaat suatu keterampilan akan menjadikan siswa memiliki tujuan dan arah dalam belajar (Coast et al., 2005). Keterampilan gerak merupakan kegiatan yang mempunyai gerak terbatas, baik gerakan tunggal maupun kelompok yang dilakukan dengan ketelitian dan ketepatan yang tinggi. Keterampilan seharusnya mendapat perhatian pada tingkat awal, dan pengajaran berlangsung berkesinambungan. Istilah terampil dapat dinyatakan untuk menggambarkan tingkat keahlian seseorang dalam melaksanakan tugas. Keterampilan gerak merupakan perwujudan dari kualitas koordinasi dan kontrol tubuh dalam melakukan gerak. Keterampilan gerak diperoleh melalui proses belajar yaitu dengan cara memahami gerakan dan melakukan gerakan berulang-ulang dengan kesadaran pikir akan benar tidaknya gerakan yang telah dilakukan (Mwivanda \& Kingi, 2019).

Bermain dalam sepakbola merupakan sarana untuk mempraktekkan dan melakukan konsolidasi konsep-konsep serta keterampilan yang telah dipelajari. Dalam hal ini bermain adalah suatu kegiatan yang dilakukan anak sendirian atau kelompok, menggunakan alat atau tidak dengan rasa gembira. Bermain adalah suatu kegiatan atau tingkah laku yang dilakukan secara sendirian atau berkelompok dengan menggunakan alat atau tidak, untuk mencapai tujuan tertentu.

Menurut Robertson et al., (2015) menyatakan bahwa pemain sepakbola membutuhkan keterampilan teknis, taktis, dan fisik untuk berhasil. Artinya, seorang pemain sepakbola harus memiliki kemampuan teknik, taktik dan keterampilan fisik yang baik untuk dapat mencapai prestasi optimal. Untuk dapat mencapai penguasaan teknik-teknik dasar bermain sepakbola pemain harus melakukan dengan prinsipprinsip gerakan teknik yang benar, cermat, sistematik yang dilakukan berulang-ulang terus menerus dan berkelanjutan, sehingga menghasilkan kerjasama yang baik antara sekumpulan saraf otot untuk pembentukan gerakan yang harmonis, sehingga menghasilkan otomatisasi gerakan (Bennike et al., 2014). Untuk dapat mencapai gerakan yang otomatis harus dimulai sejak usia muda.

Melihat kenyataan yang sebenarnya maka keterampilan teknik dasar perlu dilakukan dengan latihan yang berulang-ulang sehingga akhirnya merupakan gerakan yang otomatis. Jadi apabila seorang pemain sepakbola tidak menguasai keterampilan dasar bermain sepakbola, maka tidak akan mungkin menjadi pemain yang baik dan terkemuka. 
Metode resiprokal adalah suatu metode mengajar yang memberikan kesempatan kepada siswa untuk memberikan umpan balik kepada temannya sendiri (Edgen, \& Kauchak, 2012). Tanggung jawab untuk memberikan umpan balik bergeser dari guru kepada siswa. Pergeseran ini memungkinkan para siswa meningkatkan interaksi sosial antara teman sebayanya. Sebagaimana disebutkan Abduljabar (2011) metode mengajar resiprokal diartikan sebagai metode mengajar yang menunjukkan hubungan sosial antar teman sebaya dan kondisi untuk memberi umpan balik yang cepat. Metode ini dapat meningkatkan interaksi siswa sehingga akan lebih meningkatkan kerjasama, sehingga guru bertindak sebagai fasilator dan mengamati kemajuan teknik dan aktifitas siswa termasuk di dalamnya aktifitas dalam memberikan umpan balik (Rusman, 2012).

Kondisi pembelajaran dihubungkan dengan kegiatan pembelajaran dan peran siswa dalam melaksanakan tugas (Lardika \& Tulyakul, 2020). Kelas diatur berpasangan dengan peranan-peranan khusus untuk tiap partner. Tujuan dari metode resiprokal adalah siswa bekerja dengan pasangan dan memberikan umpan balik kepada pasangan, yang berdasarkan kriteria yang telah dipersiapkan oleh guru. Hakikat dari metode resiprokal yaitu siswa bekerja dengan pasangan, menerima umpan balik dengan segera, mengikuti kriteria yang telah dirancang guru, dan mengembangkan umpan balik dan keterampilan sosialisasinya.

\section{METODE PENELITIAN}

Penelitian ini menggunakan jenis penelitian eksperimen semu (quasi eksperiment) dengan tujuan penelitian ini untuk melihat pengaruh metode resiprokal terhadap keterampilan bermain sepakbola. Penelitian ini dilaksanakan di SMP Negeri 2 Bunut Kabupaten Pelalawan Provinsi Riau. Pada penelitian ini yang dijadikan sampel adalah seluruh siswa SMP Negeri 2 Bunut Kabupaten Pelalawan Provinsi Riau yang mengikuti kegiatan ekstrakurikuler sepakbola sebanyak 20 orang. Instrumen penelitian ini menggunakan tes keterampilan sepakbola yaitu pengembangan tes kecakapan David Lee yang merupakan pengembangan dari David Lee yang dibuat oleh Subagyo Irianto dengan harapan tes ini lebih menyempurnakan dari tes aslinya sehingga memenuhi kebutuhan/tuntutan dari kemajuan dan perkembangan sepakbola saat ini, khususnya menangani siswa SMP Negeri 2 Bunut untuk dapat melakukan evaluasi terhadap program yang telah dijalankan.

Tes ini merupakan tes rangkaian sehingga tes ini lebih sederhana baik dari segi peralatan, petugas, waktu maupun tempat/area yang digunakan. Unsur-unsur yang dinilai/diukur adalah unsur-unsur teknik dasar sepakbola yang meliputi menggiring bola, menghentikan/mengontrol bola bawah, passing/shooting. Weng et al., (2018) mengatakan, tes ini telah dinyatakan sahih, handal, dan objektif.

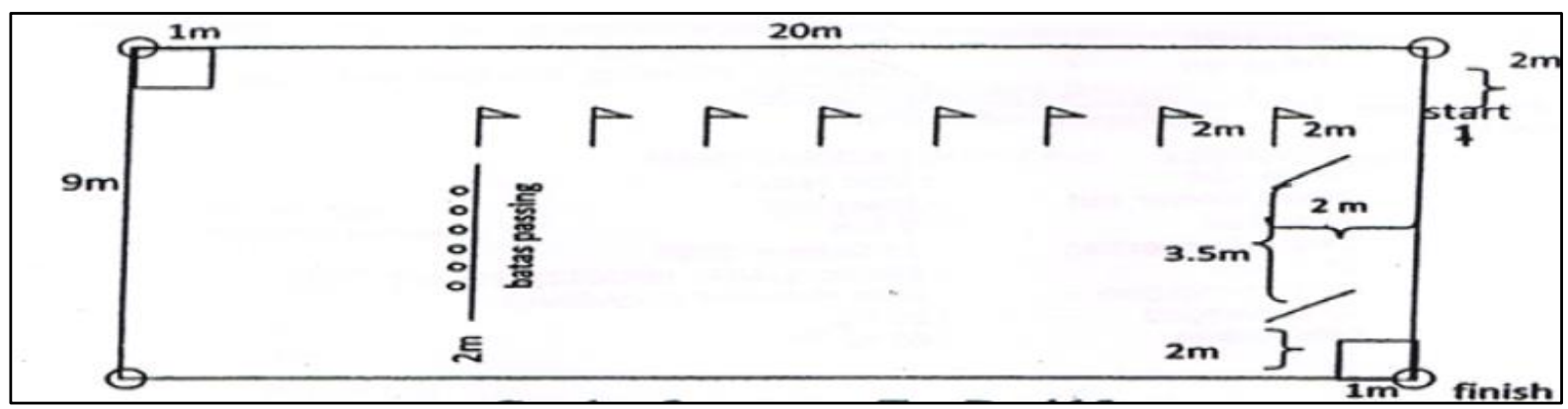

Gambar 1. Lapangan Tes Pengembangan Tes Kecakapan 


\section{HASIL PENELITIAN}

Dalam bagian ini dipaparkan mengenai hasil penelitian beserta interpretasinya. Penyajian hasil penelitian adalah berdasarkan analisis statistik yang dilakukan pada tes awal dan tes akhir keterampilan dasar bermain sepakbola.

\section{A. Hasil Tes Metode Resiprokal}

\section{Data Hasil Tes Awal Metode Resiprokal Terhadap Keterampilan Dasar Bermain Sepakbola Siswa SMP Negeri 2 Bunut Kabupaten Pelalawan Provinsi Riau}

Data hasil pengukuran data tes awal metode resiprokal ini yang terdiri dari 20 sampel $(\mathrm{n}=20)$, diperoleh keterampilan dasar bermain sepakbola dengan waktu terbaik 21.31, dan waktu terendah 32.43, skor rata-rata (mean) 27.77, median 28.19, dan simpangan baku (standar deviasi) 3.21. Agar lebih jelasnya hasil data tes awal metode resiprokal terhadap keterampilan dasar bermain sepakbola siswa SMP Negeri 2 Bunut Kabupaten Pelalawan Provinsi Riau dapat dilihat pada tabel 1.

Tabel 1. Distribusi Frekuensi Data Tes Awal Kelompok Metode Resiprokal

\begin{tabular}{cccc}
\hline No & Kelas Interval & Frekuensi Absolut & Frekuensi Relatif (\%) \\
\hline 1 & $<19.46$ & 0 & $0 \%$ \\
\hline 2 & $22.37-19.46$ & 1 & $5 \%$ \\
\hline 3 & $22.38-24.82$ & 3 & $15 \%$ \\
\hline 4 & $24.83-27.24$ & 5 & $25 \%$ \\
\hline 5 & $>27.24$ & 11 & $55 \%$ \\
\hline & Total & $\mathbf{2 0}$ & $\mathbf{1 0 0}$ \\
\hline
\end{tabular}

2. Data Hasil Tes Akhir Metode Resiprokal Terhadap Keterampilan Dasar Bermain Sepakbola Siswa SMP Negeri 2 Bunut Kabupaten Pelalawan Provinsi Riau

Data hasil pengukuran data tes akhir setelah diberikan perlakuan sebanyak 16 kali ditemukan waktu terbaik 20.12, waktu terendah 29.57, Median 25.70, skor rata-rata (mean) 25.62, dan simpangan baku (standar deviasi) 3.00. Agar lebih jelasnya hasil data metode resiprokal terhadap keterampilan dasar bermain sepakbola siswa SMP Negeri 2 Bunut Kabupaten Pelalawan Provinsi Riau dapat dilihat pada tabel 2.

Tabel 2. Distribusi Frekuensi Data Tes Akhir Kelompok Metode Resiprokal

\begin{tabular}{cccc}
\hline No & Kelas Interval & Frekuensi Absolut & Frekuensi Relatif (\%) \\
\hline 1 & $<19.46$ & 0 & $0 \%$ \\
\hline 2 & $22.37-19.46$ & 4 & $20 \%$ \\
\hline 3 & $22.38-24.82$ & 4 & $20 \%$ \\
\hline 4 & $24.83-27.24$ & 4 & $20 \%$ \\
\hline 5 & $>27.24$ & 8 & $40 \%$ \\
\hline & Total & $\mathbf{2 0}$ & $\mathbf{1 0 0}$ \\
\hline
\end{tabular}

\section{B. Pengujian Persyaratan Analisis}

Pada penelitian ini terlebih dahulu dilakukan uji persyaratan analisis dengan uji normalitas data untuk mengetahui apakah data dari variabel yang diteliti berdistribusi normal atau tidak dapat digunakan uji lilliefors dengan taraf signifikansi $\alpha=0,05$. 
Hipotesis uji lilliefors:

$\mathrm{H}_{\mathrm{o}} \quad: \mathrm{L}$ observasi $<\mathrm{L}$ tabel data berdistribusi normal

$\mathrm{H}_{\mathrm{a}} \quad$ : $\mathrm{L}$ observasi $>$ Ltabel data tidak berdistribusi normal

Tabel 3. Rangkuman Uji Normalitas Data

\begin{tabular}{cccc}
\hline Data & L $_{\text {observasi }}$ & $\mathbf{L}_{\text {tabel }}$ & Ket \\
\hline Metode Resiprokal (Tes Awal) & 0.1136 & 0.19 & Normal \\
\hline Metode Resiprokal (Tes Akhir) & 0.1175 & 0.19 & Normal \\
\hline
\end{tabular}

Pada tabel di atas menunjukkan bahwa hasil pengujian untuk data tes awal kelompok metode resiprokal adalah Lobservasi $0.1136<$ Ltabel $0.1900 \alpha=0,05$, dapat disimpulkan bahwa data berdistribusi normal. Selanjutnya hasil dari pengujian data tes akhir metode resiprokal ditemukan Lobservasi $0.1175<$ Ltabel 0.1900 , artinya data disimpulkan bahwa data berdistribusi normal.

\section{Pengujian Hipotesis}

Setelah uji persyaratan analisis dilakukan dan ternyata semua data variabel penelitian memenuhi persyaratan untuk dilakukan pengujian statistik lebih lanjut yaitu pengujian hipotesis. Berikut dideskripsikan hasil pengujian hipotesis penelitian yaitu: terdapat pengaruh metode resiprokal terhadap keterampilan dasar bermain sepakbola siswa SMP Negeri 2 Bunut Kabupaten Pelalawan Provinsi Riau.

Uji statistik yang digunakan adalah t-tes yaitu melihat pengaruh dari rata-rata hitung dengan taraf signifikan 0,05. Hasil tes awal keterampilan dasar bermain sepakbola siswa SMP Negeri 2 Bunut Kabupaten Pelalawan Provinsi Riau dengan menggunakan metode resiprokal dengan jumlah sampel 20 yang diperoleh keterampilan dasar bermain sepakbola dengan waktu terbaik 21.31, dan waktu terendah 32.43, skor rata-rata (mean) 27.77, median 28.19, dan simpangan baku (standar deviasi) 3.21. Selanjutnya hasil tes akhir keterampilan dasar bermain sepakbola setelah diberikan perlakuan sebanyak 16 kali ditemukan waktu terbaik 20.12, waktu terendah 29.57, Median 25.70, skor rata-rata (mean) 25.62, dan simpangan baku (standar deviasi) 3.00. Adapun hasil pengujian hipotesis disajikan dalam tabel 4.

Tabel 4. Rangkuman Hasil Pengujian Hipotesis Pertama

\begin{tabular}{ccccccc}
\hline Metode Resiprokal & Mean & SD & T $_{\text {hitung }}$ & T tabel & Hasil Uji & Ket \\
\hline Tes Awal & 27.77 & 3.21 & \multirow{2}{*}{17.32} & \multirow{2}{*}{1.729} & \multirow{2}{*}{ Signifikan } & $\begin{array}{c}\mathrm{H}_{\mathrm{o}} \text { ditolak dan Ha } \\
\text { diterima }\end{array}$ \\
\hline Tes Akhir & 25.62 & 3 & & & &
\end{tabular}

Berdasarkan tabel di atas, dapat dilihat bahwa $t_{\text {hitung }}=17.32>t_{\text {tabel }}=1.729$. hal ini berarti bahwa hipotesis penelitian dapat diterima. Dengan demikian dapat disimpulkan bahwa metode resiprokal memberikan pengaruh yang signifikan terhadap keterampilan dasar bermain sepakbola siswa SMP Negeri 2 Bunut Kabupaten Pelalawan Provinsi Riau. Peningkatan keterampilan dasar bermain sepakbola ini adalah sebesar 2.16 yaitu dari skor rata-rata tes awal 27.77 dan tes akhir menjadi 25.62

\section{PEMBAHASAN}

Tujuan yang ingin dicapai dalam penelitian ini adalah meningkatnya keterampilan dasar dalam bermain sepakbola di SMP Negeri 2 Bunut Kabupaten Pelalawan Provinsi Riau melalui metode resiprokal. Seorang pemain sepakbola harus memiliki kemampuan teknik, taktik dan keterampilan fisik yang baik untuk dapat mencapai prestasi optimal (Robertson et al., 2015). Agar dapat menguasai keterampilan dasar bermain sepakbola, 
siswa harus berlatih dengan benar dan kontinyu terhadap semua faktor yang menentukan atau mempengaruhi penguasaan keterampilan dasar bermain sepakbola tesebut (Rusmanto, Lardika., \& Gazali, 2020). Rendahnya keterampilan dasar bermain sepakbola tidak berdiri sendiri, hal ini dipengaruhi oleh sejumlah faktor apakah yang bersifat internal maupun eksternal (Bennike et al., 2014). Salah satu faktor eksternal yang dapat mempengaruhi yaitu metode mengajarnya. Metode resiprokal adalah suatu metode mengajar yang memberikan kesempatan kepada siswa untuk memberikan umpan balik kepada temannya sendiri (Abduljabar, 2011). Metode resiprokal adalah suatu metode mengajar yang memberikan kesempatan kepada siswa untuk memberikan umpan balik kepada temannya sendiri (Edgen \& Kauchak, 2012). Tanggung jawab untuk memberikan umpan balik bergeser dari guru kepada siswa. Pergeseran ini memungkinkan para siswa meningkatkan interaksi sosial antara teman sebayanya. Sebagaimana disebutkan Abduljabar (2011) metode mengajar resiprokal diartikan sebagai metode mengajar yang menunjukkan hubungan sosial antar teman sebaya dan kondisi untuk memberi umpan balik yang cepat. Metode ini dapat meningkatkan interaksi siswa sehingga akan lebih meningkatkan kerjasama, sehingga guru bertindak sebagai fasilator dan mengamati kemajuan teknik dan aktifitas siswa termasuk di dalamnya aktifitas dalam memberikan umpan balik (Rusman, 2012). Kelas diatur berpasangan dengan peranan-peranan khusus untuk tiap partner. Hakikat dari metode resiprokal yaitu siswa bekerja dengan pasangan, menerima umpan balik dengan segera, mengikuti kriteria yang telah dirancang guru, dan mengembangkan umpan balik dan keterampilan sosialisasinya.

\section{KESIMPULAN}

Berdasarkan hasil analisis data yang telah dikemukakan terdahulu, maka dapat diambil beberapa kesimpulan yaitu metode resiprokal memberikan pengaruh yang signifikan terhadap keterampilan dasar bermain sepakbola siswa SMP Negeri 2 Bunut Kabupaten Pelalawan Provinsi Riau. Diharapkan kepada peneliti selanjutnya untuk dapat dilakukan penelitian dengan jumlah sampel yang lebih besar.

\section{DAFTAR PUSTAKA}

Abduljabar, B. (2010). Landasan Ilmiah Pendidikan Intelektual dalam Pendidikan Jasmani. Bandung: Rizki Press.

Abduljabar, B. (2011). Modul Pedagogi Olahraga. Bandung: UPI Prodi PJKR.

Bennike, S., Wikman, J. M., \& Ottesen, L. S. (2014). Football Fitness - a new version of football? A concept for adult players in Danish football clubs. Scandinavian Journal of Medicine and Science in Sports, 24 (SUPPL.1), 138-146. https://doi.org/10.1111/sms.12276

Coast, J. R., Baronas, J. L., Morris, C., \& Willeford, K. S. (2005). The effect of football shoulder pads on pulmonary function. Journal of Sports Science and Medicine, 4(4). 
Cvetković, N., Stojanović, E., Stojiljković, N., Nikolić, D., Scanlan, A. T., \& Milanović, Z. (2018). Exercise training in overweight and obese children: Recreational football and high-intensity interval training provide similar benefits to physical fitness. Scandinavian Journal of Medicine and Science in Sports, 28. https://doi.org/10.1111/sms.13241

Edgen, P., \& Kauchak, D. (2012). Strategi dan Model Pembelajaran. Jakarta: PT Indeks.

Lardika, R. A. (2019). Effects of Kicking Nine Ball Training on Goals to Improve Shooting Accuracy Skills of Class IIIA Physical Education Students FKIP UNRI. 978-979.

Lardika, R. A., \& Tulyakul, S. (2020). The Effect of Direct Instruction Model in Physical Education Towards Students' Adversity Quotient (AQ). Journal Sport Area, 5(1), 112. https://doi.org/https://doi.org/10.25299/sportarea.2020.vol5(1).4460

Mwivanda, M., \& Kingi, P. M. (2019). Teachers' Adversity Quotient Dimension of Control and Students Academic Performance in Secondary Schools in Kenya. Journal of Education and Training, 6(1). https://doi.org/10.5296/jet.v6i1.14373

Robertson, S., Woods, C., \& Gastin, P. (2015). Predicting higher selection in elite junior Australian Rules football: The influence of physical performance and anthropometric attributes. Journal of Science and Medicine in Sport, 18(5). https://doi.org/10.1016/j.jsams.2014.07.019

Rusman. (2012). Model-Model Pembelajaran.Jakarta: PT. Raja Grafindo Persada.

Rusmanto., Lardika, R. A., \& Gazali, N. (2020). Sepakbola: Kapasitas Vital Paru dan Tingkat Kebugaran Jasmani. Journal Sport Area, 5(1), 30-39. https://doi.org/https://doi.org/10.25299/sportarea.2020.vol5(1).4791

Smith, M. P., Von Berg, A., Berdel, D., Bauer, C. P., Hoffmann, B., Koletzko, S., Nowak, D., Heinrich, J., \& Schulz, H. (2016). Physical activity is not associated with spirometric indices in lung-healthy German youth. European Respiratory Journal, 48(2). https://doi.org/10.1183/13993003.01408-2015

Weng, J., Cao, L., Xie, P., \& Wang, J. (2018). Recreational football training improved health-related physical fitness in 9- to 10-year-old boys. Journal of Sports Medicine and Physical Fitness, 58(3). https://doi.org/10.23736/S0022-4707.16.06620-2

Zainur., Lardika, R. A., Gazali, N., \& Sulastio, A. (2020). Adversity Quotient (AQ): Effect of Physical Education On Adversity Quotient Levels. International Journal of Psychosocial Rehabilitation, 24(8), 9939-9947. https://doi.org/10.37200/IJPR/V24I8/PR280987 